\title{
Inequity in the utilization of antenatal and delivery care in Yangon region, Myanmar: a cross-sectional study
}

\author{
Aye Nyein Moe Myint ${ }^{1}$, Tippawan Liabsuetraku2 ${ }^{2^{*}}$ D, Thein Thein Htay ${ }^{3}$, Myint Myint Wai ${ }^{4}$, Johanne Sundby ${ }^{5}$ \\ and Espen Bjertness ${ }^{5}$
}

\begin{abstract}
Background: Equity of access to and utilization of healthcare across socio-economic groups is important to achieve universal health coverage. Although the utilization of antenatal and delivery care has been increasing in low- and middle-income countries, inequities in the utilization of antenatal and delivery care have been reported in many countries, but have not yet been studied in Myanmar. This study aimed to determine whether inequities in the utilization of antenatal and delivery care existed in Yangon region, Myanmar.

Methods: A community-based cross-sectional survey using multistage sampling was conducted from October to November 2016. A wealth index was selected as the main socioeconomic parameter for measuring inequities with respect to early initiation of antenatal care (ANC), number of antenatal care visits, delivery by a skilled birth attendant (SBA) and delivery by cesarean section (CS). Inequities were evaluated using concentration curves and concentration indexes.

Results: Of the 762 women who gave birth within the 12-month survey period, there was no evidence of inequity in utilization of ANC; however, inequity of at least one antenatal visit among women aged less than 20 years was found with a concentration index of 0.04. The concentration indexes for delivery by SBA and CS were 0.05 and 0.14 , respectively. Delivery by CS was disproportionately higher in adolescents and women with higher education than middle school.

Conclusion: There was no overall inequity in the utilization of ANC but substantial inequities in delivery by CS and SBA were shown. Social determinants of health, particularly age and education, were associated with inequities in the utilization of delivery care. Adolescent pregnant women were found to be particularly vulnerable, and thus should be a target group for strategic plans to reduce inequities in utilization of delivery care.
\end{abstract}

Keywords: Inequity, Wealth index, Concentration index, Antenatal care, Delivery care

\section{Background}

Globally, 303,000 women died from the complications of pregnancy and childbirth in 2015 according to United Nations Sustainable Development Goals (SDGs) report 2017 [1]. Maternal deaths, deaths due to pregnancy and childbirth, remain the leading cause of death among women of reproductive age in low-income countries [2]. It has been shown that timely and appropriate antenatal

\footnotetext{
* Correspondence: Itippawa@yahoo.com

${ }^{2}$ Epidemiology Unit, Faculty of Medicine, Prince of Songkla University, Hat

Yai, Songkhla, Thailand

Full list of author information is available at the end of the article
}

care (ANC) and delivery by a skilled birth attendant (SBA) improve pregnancy outcomes and reduce maternal deaths [3]. According to the World Health Statistics SDGs report in 2017, maternal deaths and utilization of delivery care by SBA showed improvement in many countries [4]. However, disparities in the utilization of maternal health care services has been reported in many low- and middle-income countries, in most cases due to financial or socioeconomic barriers [5]. Similarly, the maternal and infant deaths has been decreasing and utilization of maternal health services have been improved in Myanmar as same as other Asian countries; 
however, these were higher than other countries such as Thailand, Singapore, and Brunei $[6,7]$.

Although the ability to seek and receive health care services should be equal for all socio-economic groups in the interests of fairness and social justice [8], either equity or inequity in the utilization of ANC and delivery care have manifested differently across countries $[5,9]$. For example, a study in Thailand showed no inequity of accessing maternal health care [9]. In contrast, there were inequities in the utilization of maternal health care services in some countries in Asia such as Vietnam, Bangladesh, and Nepal [10-12]. Substantial socioeconomic gaps, defined by wealth and level of education, were shown to be related with maternal health care services in previous studies [5, 13]; however, the analyses of inequities are limited in Myanmar.

According to the World Bank and Myanmar Demographic and Health Survey report, socio-economic indicators such as GDP per capita, poverty rates, and the utilization of ANC and delivery care have improved in recent years, but there is no evidence concerning whether inequities in the utilization of maternal health care services is better than in the past [14-16]. Strengthening universal health coverage (UHC) to reduce the financial burden on the poor and vulnerable is emphasized in the Myanmar national health plan [17, 18]. Therefore, this study aimed to determine whether inequities in the utilization of ANC and delivery care existed in Yangon region, Myanmar. The findings can lead to better understanding of whether inequity still exists or has been alleviated in utilization of maternal health care services in Myanmar which will be essential for monitoring and evaluation of maternal health in the future.

\section{ANC and delivery care in Myanmar}

The coverage of ANC and delivery care in Myanmar has been improved. The ANC coverage was increased from $63.1 \%$ in 2005 to $86.1 \%$ in 2016 . Likewise, the delivery by SBA was increased from $64.4 \%$ in 2009 to $78.4 \%$ in 2016 [19]. In the rural areas, the ANC and delivery care can be provided in the Rural Health Centers and Sub-Rural Health Centers. For urban areas, the ANC and delivery care services are provided in Primary and Secondary Health centers and Maternal and Child Health centers. Those who need referral are referred to a Station hospital in rural areas or a Township hospital in urban areas [17]. Public and private facilities are available for ANC and delivery care services but only $10 \%$ of delivery occurred in private facilities in a Public Health Statistic report in 2016 [19].

Free ANC and delivery care services were offered in both public facility-based and primary health care settings in Myanmar [17, 20]. The national budget expenditure for Maternal and Child Health function was increased nearly three times from 2009/2010 budget year to 2013/2014 budget year [20]. Although the government policy emphasized on increasing budget investment and free of charge services, there were the reports on out-of-pocket payment for ANC and delivery care [21].

\section{Methods \\ Study setting and design}

A community-based cross-sectional survey was conducted from October 2016 to November 2016 in Yangon Region of Myanmar. Yangon region located in the lower part of Myanmar having the largest population size [22] was selected to be a study area because the coverage of ANC and delivery by SBA was $95 \%$ and $83 \%$, respectively. However, high maternal mortality ratio of 213 per 100,000 live births was reported in 2016 [14, 23].

\section{Study sample, sample size and sampling methods}

Women aged 15-49 years with a history of delivery within the past 12 months residing in the selected districts were included in the sample. Mentally retarded or seriously ill women were excluded. From previous studies, the rates of ANC and delivery care utilization between the richest and poorest quintiles of the wealth index were $85 \%$ vs $95 \%$ and $51 \%$ vs $96 \%$, respectively [24]. According to higher gap difference for delivery care, we used the utilization of ANC to get the biggest samples to cover for the utilization of ANC and delivery care. The sample size was calculated based on the rate of ANC utilization between the richest and poorest quintiles of the wealth index ( $85 \%$ vs $95 \%$ ) using the two-proportion difference formula with a 95\% confidence interval and type II error of $20 \%$ [25]. According to a design effect of 2 and estimated 10\% non-response rate, at least 700 women were required for the study.

A multi-stage sampling technique was used in our study. The Yangon region is divided into four districts (north, south, west and east). West and east districts are the central part of Yangon having only urban populations. Firstly, the north and south districts were selected in our study because these two districts are the main-landed areas of Yangon including both urban and rural population. Secondly, the wards and villages within the districts were taken by proportional probability sampling (PPS) considering the actual proportion of urban and rural population accounted for $50-50 \%$ in the north districts and $30-70 \%$ in the south districts. The units of urban and rural population are wards and villages, respectively. A total of 125 wards and 235 villages are in the north district and 110 wards and 375 villages are in the south district $[26,27]$. Eight wards and eight villages in the north and south districts were randomly selected leading to a total 16 study wards and 16 study villages were randomly selected. Finally, the household having a 
woman who had delivered in the previous 12 months was randomly selected.

The household with eligible women were obtained from the immunization records which were maintained by the midwives in each ward or village which are routinely reported monthly to higher-level administrative section [28]. The immunization coverage of infants in Yangon region is more than $90 \%$ which cover infants from women delivered by SBA and traditional birth attendants [14]. The households in the selected wards and villages were visited by the research team to identify the women based on the inclusion criteria. If any household had more than one eligible woman, only one was randomly chosen for the study.

\section{Study variables}

The main study outcome was inequities in the utilization of ANC and delivery care. Inequity considering the wealth index in relation to utilization of care was determined by evaluating the concentration curve and index. The wealth index was calculated from household characteristics and assets based on the 2014 Myanmar census report using the principal component analysis and divided into five wealth quintiles, namely poorest, second, third, fourth and richest quintile [29]. Utilization of ANC was divided into utilization of at least one-visit ANC, early initiation of ANC defined as initiation of first antenatal visit within three months of gestational age and at least four-visit ANC. Utilization of delivery care included delivery by a SBA and cesarean section. Maternal characteristics including age (age in years at the time of the survey), level of education (highest level of education at the time of survey), and number of births were independent variables.

\section{Data collection}

\section{Preparatory phase}

After obtaining ethical approval, the study questionnaire was pre-tested among women aged 15-49 years with characteristics similar to the study inclusion criteria to ensure the clear meaning the variables collected in the questionnaire. The pre-test was conducted in women who were not in the study areas and the final version of questionnaire was used for data collection. A two-day workshop was held for all research assistants where they were trained in data collection before the field survey and on how to conduct a quantitative interview including checking for completeness of the information.

\section{Data collection phase}

The lists of targeted women were obtained and all eligible women were made appointment before the research team visited. The research team visited women's home and invited them to participate in our study. For the women who were not available on the day the team went to visit, we returned back for their availability until three visits. The interviews with the participating women were conducted at each woman's convenience at their home. After signing the consent forms, they were interviewed privately using the structured questionnaire by either the principal investigator or one of four trained research assistants. Data completeness was checked on a daily basis.

\section{Data analysis}

The data were recorded in EpiData 3.1 on a double entry basis [30] and the analysis was performed using $\mathrm{R}$ version 3.4.2 [31]. Categorical variables are described by frequencies and percentages. The Chi-square test was used to assess the associations between level of education and wealth quintiles. Inequities in the utilization of ANC and delivery care were determined by evaluating concentration curves and concentration indexes.

The concentration curve plotted the cumulative fraction of utilization of ANC and delivery care against the cumulative fraction of women ranked by wealth quintiles [32]. The line of equality is drawn 45 degrees diagonally from the bottom left corner to the top right corner in the concentration curve. The curve lines represented each indicator of utilization of ANC and delivery care and demonstrated how far they deviated from the line of equality. The line above the equality line indicates concentration of utilization among those who are the poorer, while the line below the equality line shows concentration of utilization among those who are the richer.

In the calculation of a concentration index, the women were ranked by increasing wealth quintiles. When a concentration index equals zero, it indicates no inequity and the theoretical maximums of a concentration index range from +1 to -1 . Negative and positive values of a concentration index show when the utilization of ANC and delivery care are concentrated among women in the poorest quintile and those in the richest quintile, respectively [33]. In our study, the concentration index of utilizing ANC and delivery care of the richest to poorest quintiles was stratified by age, level of education and number of births. A $p$ value less than 0.05 was considered as statistically significant.

\section{Results}

The response rate was $100 \%$ among the 762 women invited to participate in the study. Most participants were aged $20-34$ years and $61 \%$ had a middle school or above level of education. The women were equally distributed among the wealth quintiles. Three-fourths of the women had 1-2 children. Almost all women had received ANC at least once, and $79 \%$ had had four visits or more. Early initiation of ANC was reported in only one-third of the 
women. Of all women, $88.5 \%$ and $26.8 \%$ of them delivered with a SBA or by cesarean section, respectively (Table 1 ).

There was no evidence of inequities in utilization of ANC based on the results of the concentration curve and indexes (Fig. 1). The concentration curve was disproportionately in favor of rich women for both deliveries by a SBA and by cesarean section, with concentration indexes of 0.05 and 0.14 , respectively (Fig. 2). When the inequity among different characteristics was considered, the utilization of at least one

Table 1 Characteristics of the study women $(n=762)$

\begin{tabular}{|c|c|}
\hline Characteristic & $\mathrm{n}(\%)$ \\
\hline \multicolumn{2}{|c|}{ Background and maternal characteristics } \\
\hline \multicolumn{2}{|l|}{ Age } \\
\hline$<20$ years & $28(3.7)$ \\
\hline 20-34 years & $565(74.1)$ \\
\hline$\geq 35$ years & $169(22.2)$ \\
\hline \multicolumn{2}{|l|}{ Education } \\
\hline No formal school & $46(6.0)$ \\
\hline Primary school & $252(33.1)$ \\
\hline Middle school or above & $464(60.9)$ \\
\hline \multicolumn{2}{|l|}{ Wealth quintile } \\
\hline Poorest quintile & $153(20.1)$ \\
\hline 2nd quintile & $152(19.9)$ \\
\hline 3rd quintile & $152(19.9)$ \\
\hline 4th quintile & $152(19.9)$ \\
\hline Richest quintile & $153(20.1)$ \\
\hline \multicolumn{2}{|l|}{ No. of births } \\
\hline $1-2$ & $568(74.5)$ \\
\hline$>2$ & $194(25.5)$ \\
\hline \multicolumn{2}{|l|}{ Antenatal care characteristics } \\
\hline \multicolumn{2}{|l|}{ At least one antenatal visit } \\
\hline No & $21(2.8)$ \\
\hline Yes & $741(97.2)$ \\
\hline \multicolumn{2}{|c|}{ Early initiation of antenatal care } \\
\hline No & $506(66.4)$ \\
\hline Yes & $256(33.6)$ \\
\hline \multicolumn{2}{|l|}{ At least four antenatal visits } \\
\hline No & $162(21.3)$ \\
\hline Yes & $600(78.7)$ \\
\hline \multicolumn{2}{|l|}{ Delivery care characteristics } \\
\hline \multicolumn{2}{|c|}{ Delivery by a skilled birth attendant } \\
\hline No & $88(11.5)$ \\
\hline Yes & $674(88.5)$ \\
\hline \multicolumn{2}{|l|}{ Cesarean section } \\
\hline No & $558(73.2)$ \\
\hline Yes & 204 (26.8) \\
\hline
\end{tabular}

antenatal visit was more common in rich women aged less than 20 years (concentration index $0.04,95 \% \mathrm{CI}$ 0.001-0.079) than in the other age groups (Table 2).

Table 3 shows the inequity in the utilization of delivery care by different maternal characteristics. Delivery by a SBA among women was disproportionately concentrated among the rich women regardless of maternal characteristics. Delivery by cesarean section was more commonly found among adolescent women and those with a middle school or above who were rich. Education-related inequities for utilization of ANC and delivery care were similar to wealth-related inequities. Figure 3 shows the positive association between level of education and wealth quintiles, and it can be seen that the higher the level of education, the richer the population, and the lower the level of education, the poorer the population.

\section{Discussion}

Evidence of inequities in the overall utilization of antenatal care visits was not found, except for at least one antenatal visit in women aged less than 20 years who were rich. We identified inequities in the utilization of delivery by a SBA and cesarean section, particularly in adolescent women and women having the highest education in middle school who were rich. Similar findings of inequities were associated with education level.

No inequity in utilization of ANC found in our study was similar to studies from Thailand and Namibia, even though the wealth indexes were measured by different methods in these studies $[9,34]$. This finding in Myanmar could be explained by noting that maternal health is set as a priory public health issue and free essential drugs and services for pregnant women are provided at facilities at the township level [17, 35]. Moreover, our study counted access to ANC as including when a midwife visited a pregnant woman's home to provide ANC, which is part of the national strategy to ensure adequate services to poor and/or unknowledgeable women $[17,36]$. In contrast, inequity in utilization of ANC has been reported in some studies, for example from Malawi and India, with the main reasons of socioeconomic barriers, out-of-pocket payments and illiteracy of the women [37, 38].

We found inequities in the utilization of delivery care both for delivery by a SBA and by cesarean section, which was in accordance with studies from Namibia and rural China which explained the inequities by noting many of the women were poor and uneducated, high hospital fees, and lack of accessibility and availability, which were common in these two countries [34, 39]. A possible explanation for similar inequities in our study might be the limited availability of midwives to provide delivery services, which is different from ANC for which auxiliary midwives are available [26]. In addition, 


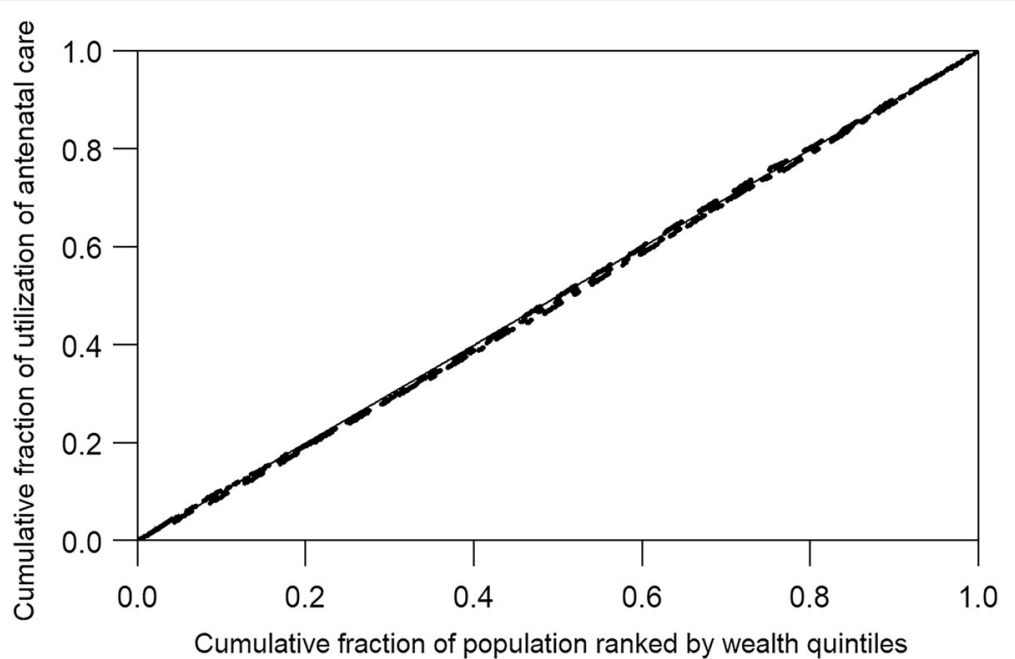

Fig. 1 Concentration curve for utilization of ANC. — Line of equality; ............. At least one antenatal visit (concentration index $=$ 0.01 ); $\mathbf{-}-\mathbf{C}$ Early initiation of antenatal care (concentration index $=0.01) ; \mathbf{-} \cdot \mathbf{-}$ - At least four antenatal visits (concentration index $=0.02$ )

out-of-pocket payments to providers for delivery care was higher than for ANC and limited access to facility-based delivery [14]. A study from Thailand indicated that equity in utilization of delivery by SBA in Thailand was achieved due to expansion of health insurance coverage and a well-functioning primary health care system [9]. For delivery by cesarean section, better access might be due to the fact that women with high socio-economic status have better opportunities to access delivery by cesarean section, which was also found a study from China [39]. Unlike ANC which is provided free of charge, delivery by cesarean section in Uganda and Argentina cost three times more than normal vaginal delivery and poor women could not afford it, which was similar in Myanmar [40].

Although we found no evidence of inequity in the utilization of ANC, the utilization of at least one antenatal visits was more common among women in the richest quintile, particularly those aged less than 20 years. We could not identify the actual reasons, but it could be related to the adolescent in richest quintile had a higher opportunity to seek for knowledge on ANC and use more the service delivery [41-44]. A systematic review published in 2017 confirmed the consistent significance of the utilization of ANC by wealth quintiles in adolescent pregnancy [45].

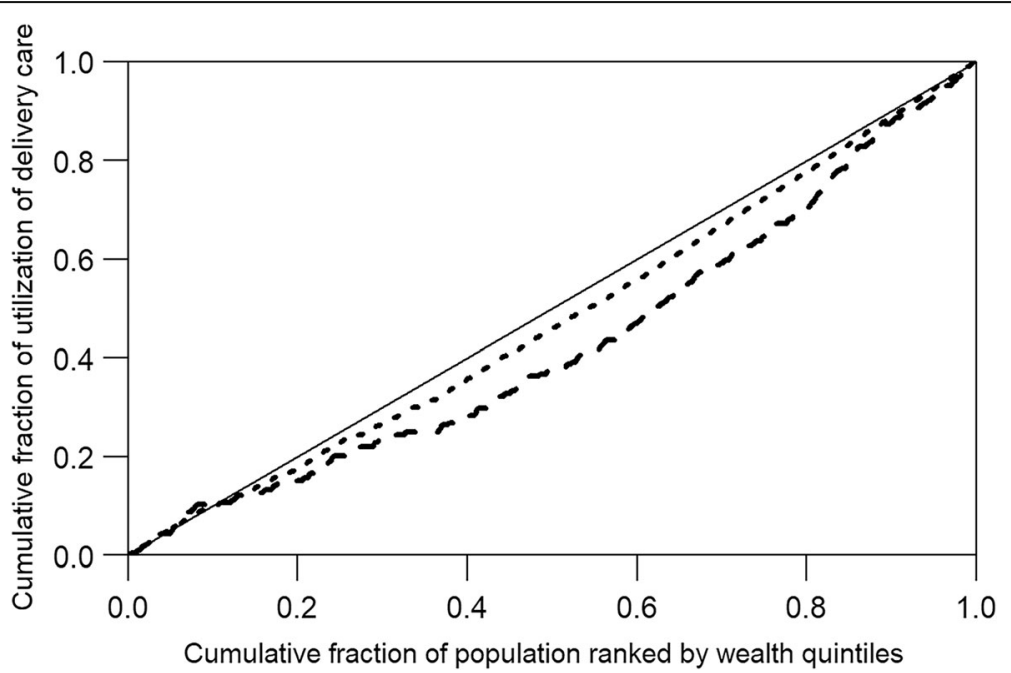

Fig. 2 Concentration curve for utilization of delivery care; Line of equality; . Delivery by a skilled birth attendant (concentration index $=0.05$ ); $-\boldsymbol{-}-\boldsymbol{Z}$ Delivery by cesarean section (concentration index $=0.14$ ) 
Table $\mathbf{2}$ Inequities in the utilization of antenatal care by different maternal characteristics

\begin{tabular}{|c|c|c|c|c|c|c|}
\hline & $\begin{array}{l}\text { Q1 (\%) } \\
\text { Poorest }\end{array}$ & Q2 (\%) & Q3 (\%) & Q4 (\%) & $\begin{array}{l}\text { Q5 (\%) } \\
\text { richest }\end{array}$ & Concentration Index (95\% Cl) \\
\hline \multicolumn{7}{|l|}{ At least one antenatal visit } \\
\hline \multicolumn{7}{|l|}{ Age } \\
\hline$<20$ years & 2.8 & 5.6 & 4.0 & 3.3 & 2.0 & $0.04(0.001,0.079)^{*}$ \\
\hline 20-34 years & 71.7 & 72.2 & 73.8 & 75.3 & 78.4 & $0.01(0.002,0.018)^{*}$ \\
\hline$\geq 35$ years & 25.5 & 22.2 & 22.2 & 21.4 & 19.6 & $0.01(-0.002,0.022)$ \\
\hline \multicolumn{7}{|l|}{ Education } \\
\hline No formal school & 12.4 & 8.3 & 4.0 & 2.7 & 1.3 & $0.02(0.001,0.040)^{*}$ \\
\hline Primary school & 57.2 & 43.1 & 28.2 & 17.3 & 19.0 & $0.01(-0.002,0.023)$ \\
\hline Middle school or above & 30.4 & 48.6 & 67.8 & 80.0 & 79.7 & $0.01(-0.002,0.010)$ \\
\hline \multicolumn{7}{|l|}{ No. of births } \\
\hline $1-2$ & 62.1 & 72.9 & 71.1 & 82.7 & 85.0 & $0.01(0.006,0.014)^{*}$ \\
\hline$>2$ & 37.9 & 27.1 & 28.9 & 17.3 & 15.0 & $0.01(0.001,0.020)^{*}$ \\
\hline \multicolumn{7}{|l|}{ Early initiation of antenatal care } \\
\hline \multicolumn{7}{|l|}{ Age } \\
\hline$<20$ years & 3.1 & 13.9 & 0.0 & 4.2 & 0.0 & $0.07(-0.087,0.227)$ \\
\hline 20-34 years & 78.1 & 60.5 & 78.3 & 83.0 & 76.8 & $0.00(-0.074,0.082)$ \\
\hline$\geq 35$ years & 18.8 & 25.6 & 21.7 & 12.8 & 23.2 & $0.00(-0.080,0.076)$ \\
\hline \multicolumn{7}{|l|}{ Education } \\
\hline No formal school & 9.4 & 11.6 & 2.2 & 4.3 & 1.8 & $0.00(-0.075,0.081)$ \\
\hline Primary school & 60.9 & 41.9 & 32.6 & 23.4 & 12.5 & $0.02(-0.039,0.079)$ \\
\hline Middle school and above & 29.7 & 46.5 & 65.2 & 72.3 & 85.7 & $-0.01(-0.069,0.049)$ \\
\hline \multicolumn{7}{|l|}{ No. of births } \\
\hline $1-2$ & 68.8 & 76.7 & 76.1 & 89.4 & 92.9 & $0.00(-0.057,0.061)$ \\
\hline$>2$ & 31.2 & 23.3 & 23.9 & 10.6 & 7.1 & $0.02(0.001,0.040)^{*}$ \\
\hline \multicolumn{7}{|l|}{ At least four antenatal visits } \\
\hline \multicolumn{7}{|l|}{ Age } \\
\hline$<20$ years & 1.8 & 6.7 & 4.0 & 3.2 & 2.3 & $0.04(-0.019,0.099)$ \\
\hline 20-34 years & 74.3 & 73.3 & 72.8 & 76.6 & 78.2 & $0.01(-0.004,0.024)$ \\
\hline$\geq 35$ years & 23.9 & 20.0 & 23.2 & 20.2 & 19.5 & $0.02(-0.019,0.059)$ \\
\hline \multicolumn{7}{|l|}{ Education } \\
\hline No formal school & 13.3 & 7.6 & 1.6 & 2.4 & 0.8 & $-0.04(-0.138,0.058)$ \\
\hline Primary school & 55.7 & 39.1 & 25.6 & 24.2 & 18.0 & $0.01(-0.029,0.049)$ \\
\hline Middle school or above & 31.0 & 53.3 & 72.8 & 81.4 & 81.2 & $0.01(-0.009,0.030)$ \\
\hline \multicolumn{7}{|l|}{ No. of births } \\
\hline $1-2$ & 64.6 & 74.3 & 74.4 & 87.9 & 85.0 & $0.02(0.001,0.040)^{*}$ \\
\hline$>2$ & 35.4 & 25.7 & 25.6 & 12.1 & 15.0 & $0.00(-0.057,0.061)$ \\
\hline
\end{tabular}

Q Quintile

$\mathrm{Cl}$ Confidence Interval

$p<0.05^{*}, p<0.01^{* *}, p<0.001^{* * *}$

Likewise, similar findings on inequities in the utilization of delivery by cesarean section could be explained by more opportunity to get a cesarean section among women who are rich and better educated [46, 47]. In general, utilization of cesarean section has been found to be higher in two groups, those with advanced maternal age and younger women who opted for a cesarean section for medical reasons [48]. Some related studies have found that richer and more educated women can access cesarean section more than the poor in some African, Latin American and Southeast Asian countries [49-51]. 
Table 3 Inequities in the utilization of delivery care by different maternal characteristics

\begin{tabular}{|c|c|c|c|c|c|c|}
\hline & $\begin{array}{l}\text { Q1 (\%) } \\
\text { Poorest }\end{array}$ & Q2 (\%) & Q3 (\%) & Q4 (\%) & $\begin{array}{l}\text { Q5 (\%) } \\
\text { richest }\end{array}$ & Concentration Index (95\% Cl) \\
\hline \multicolumn{7}{|c|}{ Delivery by a skilled birth attendant } \\
\hline \multicolumn{7}{|l|}{ Age } \\
\hline$<20$ years & 3.3 & 5.8 & 3.0 & 3.4 & 2.0 & $0.06(-0.038,0.158)$ \\
\hline 20-34 years & 71.7 & 75.2 & 73.9 & 76.3 & 78.1 & $0.04(0.020,0.060)^{* * *}$ \\
\hline$\geq 35$ years & 25.0 & 19.0 & 23.1 & 20.3 & 19.9 & $0.06(0.021,0.099)^{* *}$ \\
\hline \multicolumn{7}{|l|}{ Education } \\
\hline No formal school & 10.8 & 7.5 & 2.2 & 2.7 & 1.3 & $0.02(-0.98,0.138)$ \\
\hline Primary school & 56.7 & 38.8 & 25.4 & 16.9 & 17.9 & $0.03(-0.009,0.069)$ \\
\hline Middle school or above & 32.5 & 53.7 & 72.4 & 80.4 & 80.8 & $0.02(0.001,0.040)^{*}$ \\
\hline \multicolumn{7}{|l|}{ No. of births } \\
\hline $1-2$ & 65.8 & 75.2 & 71.6 & 83.1 & 84.8 & $0.04(0.030,0.050)^{* * *}$ \\
\hline$>2$ & 34.2 & 24.8 & 28.4 & 16.9 & 15.2 & $0.07(0.050,0.090)^{* * *}$ \\
\hline \multicolumn{7}{|l|}{ Delivery by Cesarean section } \\
\hline \multicolumn{7}{|l|}{ Age } \\
\hline$<20$ years & 3.2 & 0.0 & 0.0 & 2.1 & 1.6 & $0.25(0.211,0.289)^{* * *}$ \\
\hline 20-34 years & 64.5 & 69.2 & 71.8 & 70.2 & 67.2 & $0.13(0.071,0.189)^{* * *}$ \\
\hline$\geq 35$ years & 32.3 & 30.8 & 28.2 & 27.7 & 31.2 & $0.17(0.111,0.229)^{* * *}$ \\
\hline \multicolumn{7}{|l|}{ Education } \\
\hline No formal school & 6.4 & 11.5 & 0.0 & 4.3 & 0.0 & $0.04(-0.078,0.158)$ \\
\hline Primary school & 61.3 & 46.2 & 17.9 & 8.5 & 13.1 & $-0.07(-0.188,0.048)$ \\
\hline Middle school or above & 32.3 & 42.3 & 82.1 & 87.2 & 86.9 & $0.14(0.042,0.238)^{* *}$ \\
\hline \multicolumn{7}{|l|}{ No. of births } \\
\hline $1-2$ & 64.5 & 80.8 & 69.2 & 87.2 & 85.2 & $0.13(0.071,0.189)^{* * *}$ \\
\hline$>2$ & 35.5 & 19.2 & 30.8 & 12.8 & 14.8 & $0.11(0.012,0.208)^{*}$ \\
\hline
\end{tabular}

Q Quintile

$\mathrm{Cl}$ Confidence Interval

$p<0.05 *, p<0.01 * *, p<0.001 * * *$

Positive associations between levels of education and wealth quintiles were revealed in our study. This was not surprising, as rich women generally have higher education along with their higher incomes and they can seek what maternal healthcare they prefer [52]. The findings of inequities related to education rather than wealth were similar. The sample of women who had recently received ANC and delivery care in our study could be regarded as representative of the national situation because the essential characteristics of the women in our study were similar to those described in the results of the Myanmar Demographic and Health Survey 2015 [14]. For determining inequity, we found, as with an earlier study, that accessing data on household assets to create a wealth index was easier and more accurate than accessing data on household income and also provides a relevant measurement for people in low- and middle-income countries [5]. All women responded well to the interview in this study and the response rate was $100 \%$.
There were some limitations of the study. First, this was a cross-sectional study to compare the utilization of ANC and delivery care between poor and rich women using a wealth index; therefore, any potential causal relationship was not definitely determined. Second, the list of women who delivered may have missed some women, but this missing figure, if any, should be small because we retrieved the lists of women who had recently delivered from immunization registers and birth registries, which included women who had and had not delivered by a SBA. Third, the data on utilization of ANC and delivery care were obtained by women's self-reported experiences, which could have resulted in some recall bias. However, this bias would be minimized because we were only seeking data on the most recent delivery within the previous 12 months. Finally, only the inequity in different subgroups was explored, not testing for the factors associated with the inequities in the utilization of antenatal and delivery care which can be conducted in the future. 


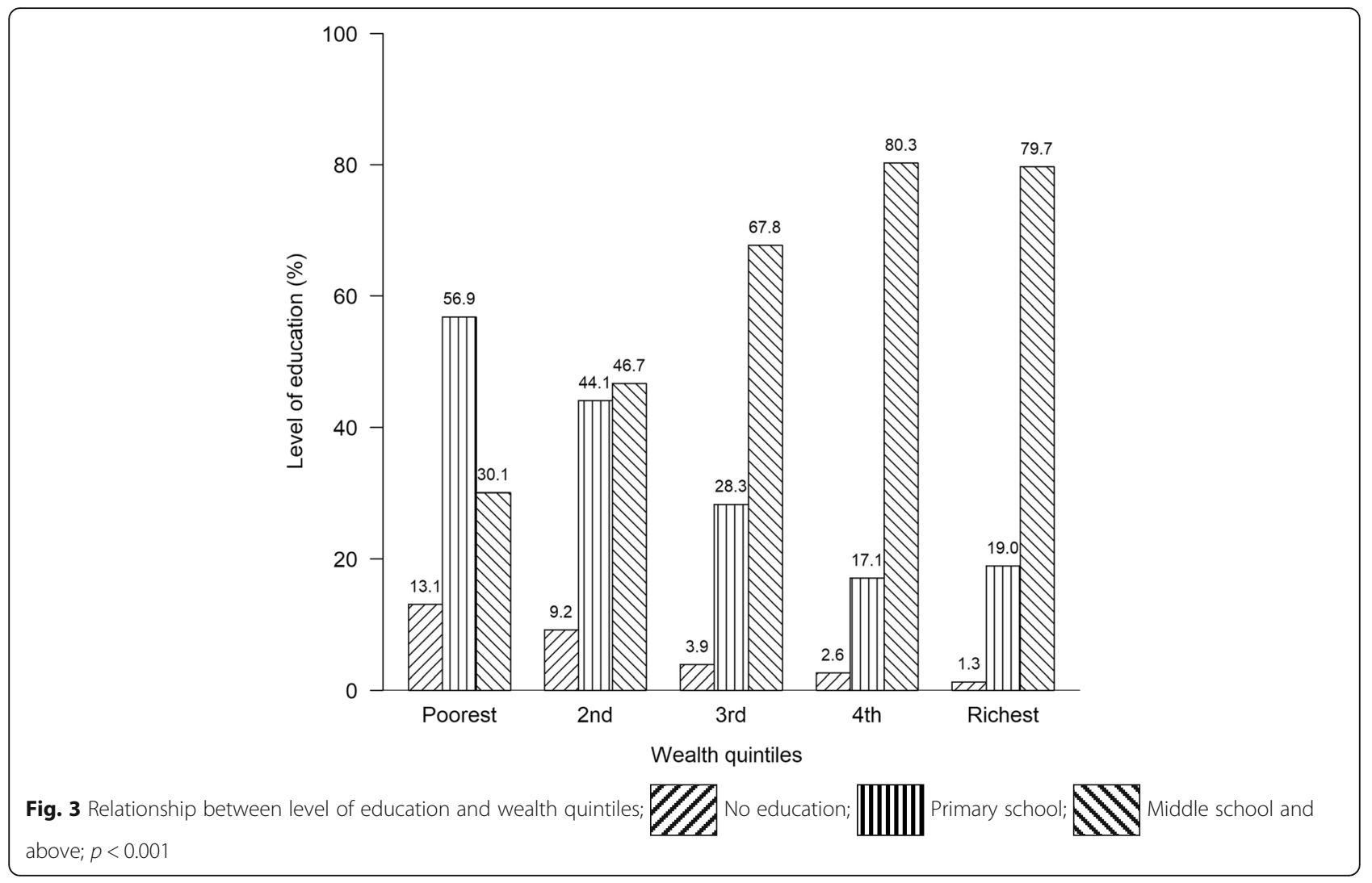

\section{Conclusion}

There were no overall inequities in the utilization of ANC, but inequities were substantially found in women who had delivery by cesarean section and/or delivery by a SBA. We suggest that adolescent pregnant women should be the target group to reduce inequity in utilization of delivery care. Appropriate strategies relevant to country context regarding pregnant women in the low wealth index group should be studied to improve the utilization of delivery care.

\section{Acknowledgements}

This study was a part of the thesis of the first author to fulfill the requirements of the doctoral degree in Epidemiology at Prince of Songkla University. We would like to thank the Regional Department of Yangon for their permission to undertake the study and their support in obtaining the lists of women.

\section{Funding}

The study was supported by a grant from the Norwegian Programme for Capacity Development in Higher Education and Research for Development (NORHED) through the project entitled "Health and Sustainable Development in Myanmar - Competence Building in Public Health (MY-NORTH)".

\section{Authors' contributions}

All authors contributed to the concept and design of the study. ANMM and TL participated in data collection, data analysis, interpretation of the data, and preparation of the draft manuscript. TTH, MMW, JS and EB also assisted with interpretation of the data and commented on the draft MS. All authors read and approved the final manuscript.
Ethics approval and consent to participate

Ethical clearances were obtained from the Ethical Review Committee of Prince of Songkla University, Thailand, the Department of Medical Research, Myanmar and the Norwegian National Research Ethics Committee (NSD), Norway.

\section{Competing interests}

The authors declare that they have no competing interests.

\section{Publisher's Note}

Springer Nature remains neutral with regard to jurisdictional claims in published maps and institutional affiliations.

\section{Author details}

'International Relations Division, Ministry of Health and Sports, Nay Pyi Taw, Myanmar. ${ }^{2}$ Epidemiology Unit, Faculty of Medicine, Prince of Songkla University, Hat Yai, Songkhla, Thailand. ${ }^{3}$ Ministry of Health and Sports, Nay Pyi Taw, Myanmar. ${ }^{4}$ Department of Medical Services (Planning), Ministry of Health and Sports, Nay Pyi Taw, Myanmar. ${ }^{5}$ Department of Community Medicine and Global Health, University of Oslo, Oslo, Norway.

Received: 22 February 2018 Accepted: 16 May 2018

Published online: 22 May 2018

\section{References}

1. United Nations. The sustainable development goals report 2017. New York: UN; 2017.

2. World Health Organization. The world health report 2008. Geneva: WHO; 2008.

3. World Health Organization. WHO fact sheet on maternal mortality. Geneva: WHO; 2016

4. World Health Organization. World health statistics 2017: monitoring health for the SDGs, sustainable development goals. Geneva: WHO; 2017.

5. Houweling TA, Ronsmans C, Campbell OM, Kunst AE. Huge poor-rich inequalities in maternity care: an international comparative study of 
maternity and child care in developing countries. Bull World Health Organ. 2007:85:745-54.

6. World Health Organization. Trends in maternal mortality: 1990 to 2015 . Geneva: WHO; 2015

7. United Nations Children's Fund. Levels \& trends in child mortality report 2015. New York: UNICEF; 2015.

8. van der Hoog M. Measuring equity in health care delivery: a new method based on the concept of aristotelian equality. Netherlands: Network for studies on pensions, aging and retirement; 2010.

9. Limwattananon S, Tangcharoensathien V, Prakongsai P. Equity in maternal and child health in Thailand. Bull World Health Organ. 2010;88:420-7.

10. Bhatta DN, Aryal UR. Paternal factors and inequity associated with access to maternal health care service utilization in Nepal: a community based crosssectional study. PLoS One. 2015;10:e0130380.

11. Anwar I, Sami M, Akhtar N, Chowdhury ME, Salma U, Rahmanc M, et al. Inequity in maternal health-care services: evidence from home-based skilled-birth-attendant programmes in Bangladesh. Bull World Health Organ. 2008;86:252-9

12. Goland E, Hoa DT, Målqvist M. Inequity in maternal health care utilization in Vietnam. Int J Equity Health. 2012;11:24.

13. Bobo FT, Yesuf EA, Woldie M. Inequities in utilization of reproductive and maternal health services in Ethiopia. Int J Equity Health. 2017;16:150.

14. Myanmar Ministry of Health and Sports. Myanmar demographic and health survey 2015-2016. Nay Pyi Taw: Ministry of Health and Sports; 2016.

15. World Bank. Myanmar overview. Washington DC: World Bank; 2017.

16. World Health Organization. How can health equity be improved in Myanmar? Geneva: WHO; 2015

17. Myanmar Ministry of Health. Health in Myanmar 2014. Nay Pyi Taw: Ministry of Health; 2014.

18. Myanmar Ministry of Health and Sports. Myanmar national health plan 2017-2021. Nay Pyi Taw: Ministry of Health and Sports; 2016.

19. Myanmar Ministry of Health and Sports. Public health statistics (2014-2016). Nay Pyi Taw: Ministry of Health and Sports; 2016. p. 105.

20. World Bank. Myanmar: public expenditure review 2015. Washington DC: World Bank; 2015

21. Wai-Wai-Han, Saw-Saw, Hla-Mya-Thwe-Einda, Nyi-Nyi-Zayar, Phyu-Phyu-Aye, Hnin-Le-Yi-Khaing, et al. Out of pocket expenditure on maternal and child health care services among rural households in dedaye township, Myanmar. Myanmar Med J. 2017:59:1-45.

22. Myanmar Ministry of Immigration and Population. Yangon region census report. Nay Pyi Taw: Ministry of Immigration and Population; 2014

23. Myanmar Ministry of Labour Immigration and Population. Thematic report on maternal mortality. Nay Pyi Taw: Ministry of Labour, Immigration and Population; 2016.

24. Myanmar Ministry of National Planning and Economic Development, Ministry of Health, UNICEF. Myanmar multiple indicator cluster survey 20092010. Nay Pyi Taw: Ministry of Health; 2011.

25. World Health Organization. Sample size determination in health studies practical manual. Geneva: WHO; 1991.

26. Myanmar Ministry of Home Affairs. Myanmar administrative structure. Nay Pyi Taw: Ministry of Home Affairs; 2016.

27. Myanmar Ministry of Home Affairs. The ward or village-tract administration law. Nay Pyi Taw: Ministry of Health and Sports; 2012

28. Myanmar Ministry of Health. Health management information system (public health). Nay Pyi Taw: Ministry of Health; 2012

29. Fry K, Firestone R, Chakraborty N. Measuring equity with national representative wealth quintiles. Washington DC: Population Services International (PSI); 2014.

30. Lauritsen JM, Bruus M. EpiData entry. Denmark: Odense; 2005.

31. R Core Team. R: a language and environment for statistical computing Vienna: R foundation for statistical computing; 2015.

32. O'Donnell O, van Doorslaer E, Wagstaff A, Lindelow M. Analyzing health equity using household survey data: a guide to techniques and their implementation. Washington DC: World Bank; 2008.

33. World Health Organization. Health inequality monitoring with a special focus on low- and middle-income countries. Geneva: WHO; 2013.

34. Zere E, Tumusiime P, Walker O, Kirigia J, Mwikisa C, Mbeeli T. Inequities in utilization of maternal health interventions in Namibia: implications for progress towards MDG 5 targets. Int J Equity Health. 2010;9:16.

35. World Bank. Myanmar essential health services access project. Washington DC: World Bank; 2014.
36. Khan S, Timmings C, Vogel J, Ba-Thike K, Moore J, Gülmezoglu M, et al. GREAT project [guideline-driven, research priorities, evidence synthesis, application of evidence, and transfer of knowledge]. Geneva: WHO; 2012.

37. Goli S, Doshi R, Perianayagam A. Pathways of economic inequalities in maternal and child health in urban India: a decomposition analysis. PLoS One. 2013;8:e58573.

38. Yaya S, Bishwajit G, Shah V. Wealth, education and urban-rural inequality and maternal healthcare service usage in Malawi. BMJ Glob Health. 2016;1: e000085.

39. Shen Y, Yan H, Reija K, Li Q, Xiao S, Gao J, et al. Equity in use of maternal health services in western rural China: a survey from Shaanxi province. BMC Health Serv Res. 2014;14:155.

40. Borghi J. What is the cost of maternal health care and how can it be financed? Stud HSO\&P. 2001;17:243-92.

41. Reynolds HW, Wong EL, Tucker H. Adolescents' use of maternal and child health services in developing dountries. Int Fam Plan Perspect. 2006;32:6-16.

42. Makii MA. Utilization of antenatal care services among adolescent mothers in mathare informal settlement, Nairobi country, Kenya. Kenya: Kenyatta Univerity; 2006

43. Owolabi OO, Wong KLM, Dennis ML, Radovich E, Cavallaro FL, Lynch CA, et al. Comparing the use and content of antenatal care in adolescent and older first-time mothers in 13 countries of West Africa: a cross-sectional analysis of demographic and health surveys. Lancet Child Adolesc Health. 2017;1:203-12.

44. Haque M. Individual's characteristics affecting maternal health services utilization: married adolescents and their use of maternal health services in Bangladesh. Internet J Health. 2009:8:1-11.

45. Banke-Thomas OE, Banke-Thomas AO, Ameh CA. Factors influencing utilisation of maternal health services by adolescent mothers in low-and middle-income countries: a systematic review. BMC Pregnancy Childbirth. 2017:17:65.

46. Mehata S, Paudel YR, Dariang M, Aryal KK, Lal BK, Khanal MN, et al. Trends and inequalities in use of maternal health care services in Nepal: strategy in the search for improvements. Biomed Res Int. 2017;2017

47. Magadi M, Agwanda A, Obare F, Taffa N. Comparing maternal health indicators between teenagers and older women in sub-saharan Africa: evidence from DHS. Southampton: Southampton Statistical Sciences Research Institute; 2003. p1-35.

48. Janoudi G, Kelly S, Yasseen A, Hamam H, Moretti F, Walker M. Factors associated with increased rates of caesarean section in women of advanced maternal age. J Obstet Gynaecol Can. 2015;37:517-26.

49. Gilbert A, Benjamin A, Abenhaim HA. Does education level influence the decision to undergo elective repeat caesarean section among women with a previous caesarean section? J Obstet Gynaecol Can. 2010;32:942-7.

50. Leone T, Padmadas SS, Matthews Z. Community factors affecting rising caesarean section rates in developing countries: an analysis of six countries. Soc Sci Med. 2008;67:1236-46.

51. Ronsmans C, Holtz S, Stanton C. Socioeconomic differentials in caesarean rates in developing countries: a retrospective analysis. Lancet. 2006;368: $1516-23$.

52. Yar'zever IS, Said IY. Knowledge and barriers in utilization of maternal health care services in Kano state, northern Nigeria. Eur J Biol Med Sci Res. 2013;1:1-14.

Ready to submit your research? Choose BMC and benefit from:

- fast, convenient online submission

- thorough peer review by experienced researchers in your field

- rapid publication on acceptance

- support for research data, including large and complex data types

- gold Open Access which fosters wider collaboration and increased citations

- maximum visibility for your research: over $100 \mathrm{M}$ website views per year

At BMC, research is always in progress.

Learn more biomedcentral.com/submissions 